\title{
Latihan Berjalan untuk Menurunkan Tekanan Darah pada Penderita Hipertensi
}

\author{
Ni Made Ridla Nilasanti*, Tasnim \\ Poltekkes Kemenkes Palu, Prodi D-III Keperawatan Poso \\ *Email korespondensi: karenmargareth08@gmail.com
}

DOI: 10.33860/pjpm.v2i1.103

\section{History Artikel}

Received: 17-06-2020

Accepted: $10-12-2020$

Published: 31-01-2021

Kata kunci:

Hipertensi, Latihan

Berjalan

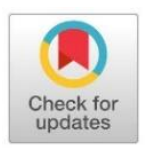

\section{Keywords:}

Hypertension, Walking Exercise

\section{ABSTRAK}

World Health Organization (WHO) (2015), menunjukkan bahwa sekitar 1,13 miliar orang di dunia menderita hipertensi. Diperkirakan pada tahun 2025 akan ada 1,5 Miliar orang yang terkena hipertensi, dan diperkirakan setiap tahunnya 10,44 juta orang meninggal akibat hipertensi dan komplikasinya. Sebanyak $34,1 \%$ penduduk Indonesia berumur $>18$ tahun menderita hipertensi. Sulawesi Tengah pada tahun 2017 dari 76.911 jiwa penduduk usia $\geq 18$ tahun, sebesar 3.436 yang diukur tekanan darahnya terdapat 2.711 jiwa yang menderita Hipertensi (78,9\%). Prevalensi hipertensi di kabupaten Poso pada tahun 2017 sebesar 12,85\%. Metode yang digunakan dalam pengabdian masyarakat ini meliputi pemeriksaan tanda-tanda vital, kadar kolestrol darah dan mengecek status pernapasan (dispnea atau nyeri dada), ceramah dan diskusi, demonstrasi dan pelaksanaan Latihan Berjalan. Hasil kegiatan ini, dari 15 peserta ada 10 peserta yang mengalami penurunan tekanan dan 5 peserta tidak mengalami perubahan tekanan darah sistol. Ada 7 orang peserta yang mengalami penurunan tekanan darah diastole dan 8 orang peserta memiliki tekanan darah diastole yang sama sebelum dan sesudah latihan berjalan. Kesimpulan: Latihan berjalan dapat menurunkan tekanan darah pada penderita hipertensi. Saran: Masyarakat terutama penderita hipertensi agar dapat melakukan latihan berjalan sebagai salah satu alternatif yang mudah, murah, efektif dan efisien untuk menurunkan tekanan darah

\section{ABSTRACT}

World Health Organization (WHO) (2015), shows that around 1.13 billion people in the world suffer from hypertension. It is estimated that in 2025 there will be 1.5 million people who are estimated to have hypertension, and it is estimated that every year 10.44 million people die from hypertension and its complications. As many as $34.1 \%$ of Indonesia's population $>18$ years old suffer from hypertension. Central Sulawesi in 2017 out of 76,911 people aged $\geq 18$ years, amounted to 3,436 which means that blood pressure was 2,711 people suffering from hypertension (78.9\%). The prevalence of hypertension in Poso district in 2017 is $12.85 \%$. The methods used in community service include: Examining vital signs, blood cholesterol levels and checking respiratory status (dyspnea or chest pain), Lectures and Discussions, Demonstrations and Implementation of Walking Exercise. Results: From 15 participants 10 participants experienced a decrease in pressure and 5 participants did not experience changes in systolic blood pressure. 7 participants experienced a decrease in diastolic blood pressure and 8 participants had the same diastolic blood pressure before and after the walking exercise. Conclusion: Exercise walking can reduce blood pressure in people with hypertension. Suggestion: People especially hypertension sufferers should be able to do walking exercises as an easy, cheap, effective and efficient alternative to reduce blood pressure.

(C) 2021 by the authors. Submitted for possible open access publication under the terms and conditions of the Creative

Commons Attribution (CC BY SA) license (https://creativecommons.org/licenses/by-sa/4.0/) 


\section{PENDAHULUAN}

Hipertensi sudah menjadi masalah kesehatan masyarakat (public health problem) dan akan menjadi masalah yang lebih besar jika tidak ditanggulangi sejak dini (Kementerian Kesehatan R.I., 2016). Sekitar 1,13 miliar orang di dunia menderita hipertensi. Artinya bahwa 1 dari 3 orang di dunia menderita hipertensi. Diperkirakan pada tahun 2025 akan ada 1,5 Miliar orang yang terkena hipertensi, dan diperkirakan setiap tahunnya 10,44 juta orang meninggal akibat hipertensi dan komplikasinya (World Health Organization, 2019). Dari 57 juta angka kematian pada tahun 2008, 63\% diantaranya disebabkan karena Noncommunicable Disease (NCDs) dan sebagian besar (48\%) adalah karena penyakit jantung dan pembuluh darah, kemudian diikuti oleh kanker $(21 \%)$ dan penyakit pernapasan kronis $(3.5 \%)$. Berdasarkan pengukuran tekanan darah, didapati sebanyak $34,1 \%$ penduduk Indonesia berumur $>18$ tahun menderita hipertensi (Kementerian Kesehatan R.I., 2018). Pada tahun 2017 dari 76.911 jiwa penduduk usia $\geq 18$ tahun, sebesar 3.436 yang diukur tekanan darahnya terdapat 2.711 jiwa yang menderita Hipertensi (78,9\%). Prevalensi hipertensi di kabupaten Poso pada tahun 2017 sebesar 12,85\% (Dinas Kesehatan Propinsi Sulawesi Tengah, 2017). Kondisi ini menimbulkan tantangan tersendiri bagi para tenaga kesehatan yang berada di Sulawesi Tengah untuk memaksimalkan upaya pelayanan dan pencegahan tingkat lanjut.

Sejak tahun 1983 WHO telah merekomendasikan penggunaan pendekatan non farmakologi dalam pengobatan primer untuk hipertesi. Diperlukan pengendalian faktor risiko hipertensi, modifikasi gaya hidup pada penderita hipertensi sangat diperlukan salah satunya adalah melakukan kebiasaan berolahraga. Penelitian oleh Nicholles menyatakan bahwa pengobatan non farmakologi yang paling tepat untuk penderita hipertensi adalah aktivitas fisik atau berolahraga. Menurut (JNC 7) kunci dari pengobatan hipertensi adalah modifikasi gaya hidup, salah satunya dengan cara berjalan kaki santai selama minimal 30 menit sehari dan dilakukan beberapa kali perminggu (Chobanian et al., 2003). Latihan berjalan merupakan olahraga yang yang bersifat ringan, sederhana, murah dan dapat dilakukan oleh pasien hipertensi di semua usia. Dalam penelitian sebelumnya telah membuktikan bahwa olahraga yang paling tepat untuk menurunkan tekanan darah pada pasien hipertensi adalah kombinasi antara berjalan kaki, jogging dan bersepeda. Tetapi terdapat beberapa risiko mungkin terjadi apabila melakukan olahraga yang seperti jogging dan bersepeda. Selain itu kebanyakan pasien hipertensi memiliki berat badan yang berlebih sehingga untuk melakukan olahraga berat bukan suatu hal yang mudah untuk dilakukan.

Hasil wawancara dengan beberapa pasien hipertensi, menunjukkan bahwa permasalahan yang sering muncul adalah banyaknya masyarakat yang sudah mengenal tentang penyakit hipertensi, namun masih banyak persepsi maupun anggapan tentang penyakit ini yang kurang tepat. Masyarakat beranggapan bahwa dengan pengobatan farmakologi pasien tidak perlu untuk memodifikasi gaya hidup, sehingga pola makan, diet dan olahraga bukan menjadi prioritas utama dalam pengobatan hipertensi. Salah satu upaya yang dapat dilakukan perawat untuk menekan prevalensi tersebut dengan menerapkan intervensi modifikasi gaya hidup, dengan meningkatkan kesadaran pasien untuk mengidentifikasi faktor risiko dan melakukan manajemen preventif untuk faktor risiko tersebut. Tujuan dari kegiatan pengabdian kepada masyarakat ini adalah untuk mendorong lansia yang menderita hipertensi untuk melakukan latihan berjalan guna menurunkan tekanan darah. 


\section{METODE PELAKSANAAN}

Kegiatan dilaksanakan pada tanggal 20 September 2019 di Balai Kelurahan Lawanga. Khalayak sasaran adalah penderita hipertensi di Kelurahan Lawanga. Kegiatannya berupa pemeriksaan tanda-tanda vital, kadar kolestrol darah dan mengecek status pernapasan (dispnea atau nyeri dada), ceramah dan diskusi untuk memberikan pemahaman peserta tentang latihan berjalan sebagai upaya menurunkan tekanan darah pada pasien hipertensi, demonstrasi yaitu peneliti dibantu oleh mahasiswa menunjukan contoh bagaimana cara melaksanakan latihan berjalan, dan pelaksanaan latihan berjalan dengan meminta peserta untuk mempraktekan secara langsung latihan berjalan selama 30 - 45 menit di dampingi langsung oleh dosen dan juga mahasiswa Prodi Keperawatan Poso.

\section{HASIL DAN PEMBAHASAN}

Kegiatan pengabdian ini diawali dengan pemeriksaan tanda-tanda vital, kadar kolestrol darah, tekanan darah dan status pernapasan (gambar 1), kemudian dilanjutkan dengan pemberian penyuluhan dan diskusi tentang penyakit hipertensi dan cara pencegahannya (gambar 2), dan diakhiri dengan latihan berjalan bersama para peserta (gambar 3)

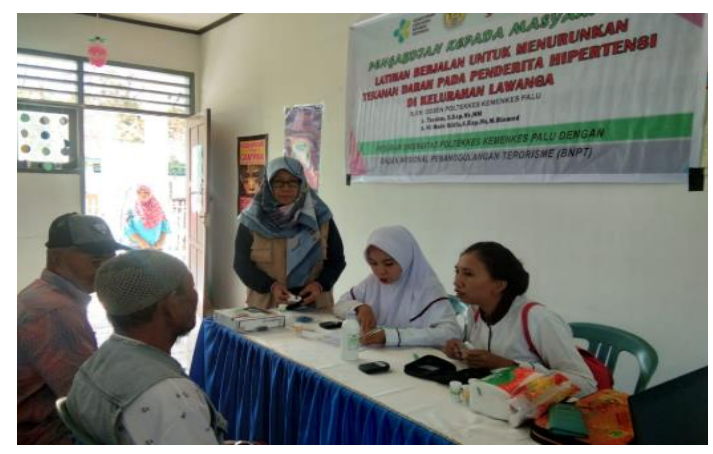

Gambar 1. Pemeriksaan tanda-tanda vital, kadar kolestrol darah, tekanan darah dan status pernapasan

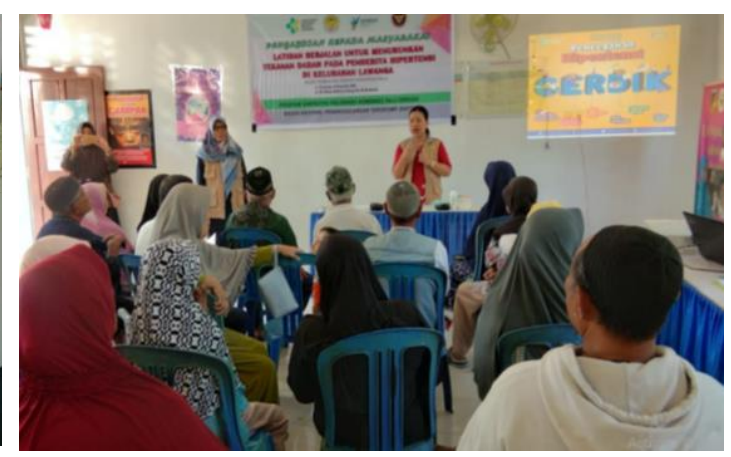

Gambar 2: Melakukan penyuluhan dan Diskusi tentang Penyakit Hipertensi dan Latihan Berjalan

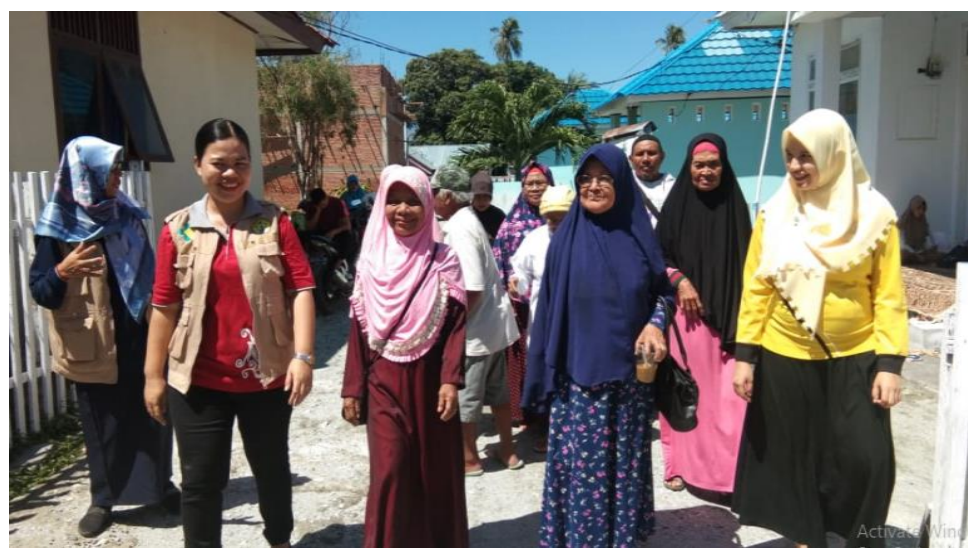

Gambar 3. Latihan Berjalan Bersama Penderita Hipertensi di Kelurahan Lawanga 
Berdasarkan tabel 1 terlihat bahwa dari 15 peserta latihan berjalan ada 10 peserta yang mengalami penurunan tekanan darah sistol setelah latihan berjalan, dan 5 peserta tidak mengalami perubahan tekanan darah sistol setelah latihan berjalan. Penurunan tekanan darah diastole terjadi pada 7 orang peserta setelah melakukan latihan berjalan, dan 8 orang peserta memiliki tekanan darah diastole yang tetap sebelum dan sesudah latihan berjalan

Tabel 1. Distribusi Frekuensi Peserta berdasarkan Pengukuran Tekanan Darah (TD) Sebelum dan Sesudah Melakukan Latihan Berjalan di Kelurahan Lawanga

\begin{tabular}{ccclccc}
\hline No & $\begin{array}{c}\text { TD Sistolik } \\
\text { Sebelum } \\
(\mathbf{m m H g})\end{array}$ & $\begin{array}{c}\text { TD Sistolik } \\
\text { Setelah } \\
(\mathbf{m m H g})\end{array}$ & Ket & $\begin{array}{c}\text { TD Diastolik } \\
\text { Sebelum } \\
\text { (mmHg) }\end{array}$ & $\begin{array}{c}\text { TD Diastolik } \\
\text { Setelah } \\
\text { (mmHg) }\end{array}$ & Ket \\
\hline 1 & 170 & 165 & Turun & 90 & 80 & Turun \\
2 & 140 & 130 & Turun & 70 & 70 & Tetap \\
3 & 160 & 160 & Tetap & 80 & 80 & Tetap \\
4 & 165 & 165 & Tetap & 70 & 70 & Tetap \\
5 & 145 & 145 & Tetap & 80 & 80 & Tetap \\
6 & 140 & 130 & Turun & 100 & 90 & Turun \\
7 & 140 & 130 & Turun & 75 & 70 & Turun \\
8 & 160 & 160 & Tetap & 85 & 80 & Turun \\
9 & 140 & 130 & Turun & 80 & 80 & Tetap \\
10 & 165 & 140 & Turun & 90 & 80 & Turun \\
11 & 170 & 160 & Turun & 100 & 90 & Turun \\
12 & 155 & 155 & Tetap & 75 & 75 & Tetap \\
13 & 160 & 140 & Turun & 90 & 80 & Turun \\
14 & 140 & 130 & Turun & 70 & 70 & Tetap \\
15 & 155 & 135 & Turun & 70 & 70 & Tetap \\
\hline
\end{tabular}

Kebiasaan berolahraga jalan kaki merupakan suatu aktivitas aerobik yang bermanfaat untuk meningkatkan dan mempertahankan daya tahan Kardiovaskular serta Muskuloskeletal. Dengan latihan fisik yang benar dan teratur akan terjadi efisiensi kerja jantung. Kemampuan jantung akan meningkat sesuai dengan perubahan- perubahan yang terjadi pada tubuh. Hal tersebut dapat berupa perubahan pada frekuensi jantung, isi sekuncup, dan curah jantung.

Penelitian Rezky et al. juga menyatakan jalan kaki selama 30 menit terbukti dapat menurunkan tekanan darah secara signifikan pada lansia (Rezky et al., 2019). Terdapat hubungan berolahraga terutama jalan kaki dengan tekanan darah pada hipertensi, terdapat penurunan tekanan darah sistolik sebesar 9,0\% dan diastolik sebesar $7,42 \%$ pada pasien hipertensi yang mendapatkan intervensi berjalan kaki selama 30 menit setiap harinya (Larasiska \& Priyantari HN, 2017; Sohn et al., 2007)

Saat melakukan aktivitas fisik yang bersifat aerobik seperti berjalan kaki, tekanan darah akan naik cukup banyak. Seperti pada saat melakukan olahraga aerobik yang bersifat keras, tekanan darah sistolik akan naik mejadi $150-200 \mathrm{mmH}$ dari tekanan darah sistolik ketika istirahat sebesar $110-120 \mathrm{mmHg}$. sebaliknya, segera setelah latihan aerobik selesai, tekanan darah akan turun sampai di bawah normal dan berlangsung selama 30-120 menit. Jika aktivitas fisik yang bersifat aerobik ini dilakukan secara berulang, penurunan tekanan darah akan berlangsung lebih lama. Itulah sebabnya berolahraga secara terarur akan dapat menurunkan tekanan darah. Jenis olahraga yang efektif menurunkan tekanan darah adalah olahraga aerobik dengan intensitas sedang dengan frekuensi 3-5 kali perminggu dengan durasi latihan minimal 30 menit sekali latihan. 
Sejalan dengan hal ini, penelitian Surbakti yang mengemukakan bahwa latihan berjalan secara signifikan menurunkan tekanan darah. Penurunan tekanan darah pada pasien hipertensi setelah latihan jalan kaki disebabkan karena terjadinya beberapa mekanisme dalam tubuh yaitu penurunan aktivitas sistim saraf simpatis, penurunan resistensi total perifer vaskular, penurunan curah jantung, meningkatnya sensitivitas barorefleks dan menurunnya volume plasma (Surbakti, 2014). Latihan berdampak positif pada perbaikan fungsi autonomi jantung klien gagal jantung di ukur menggunakan variable heart rate recovery dan heart rate variability (Yu et al., 2007). Asumsi peneliti, pasien hipertensi yang rajin melakukan latihan berjalan dapat membuat kemampuan otot jantung melakukan kontraksi lebih baik dibandingkan dengan pasien hipertensi yang kurang aktifitas. Kondisi ini yang memicu jantung berkontraksi lebih sedikit untuk memompakan darah dengan volume yang sama. Dengan melakukan latihan berjalan secara terus menerus akan menurunkan curah jantung dan secara langsung dapat menurunkan tekanan darah.

\section{KESIMPULAN}

Latihan berjalan dapat menurunkan tekanan darah pada 10 dari 15 penderita hipertensi di Kelurahan Lawanga Kecamatan Poso Kota.

\section{UCAPAN TERIMA KASIH}

Penulis mengucapkan terima kasih kepada Kepala Kelurahan Lawanga, Kader Posyandu Lansia Kelurahan Lawanga yang telah mendukung kegiatan ini sehingga bisa berjalan dengan baik dan lancar, dan juga kepada pihak Poltekkes Kemenkes Palu yang telah memberi dukungan dana untuk pelaksanaan kegiatan pengabdian masyarakat ini.

\section{DAFTAR PUSTAKA}

Chobanian, A. V., Bakris, G. L., Black, H. R., Cushman, W. C., Green, L. A., Jr, J. L. I., Jones, D. W., Materson, B. J., Oparil, S., Jr, J. T. W., \& Roccella, E. J. (2003). The Seventh Report of the Joint National Committee on Prevention, Detection, Evaluation, and Treatment of High Blood Pressure. JAMA, 289(19), 2560. https://doi.org/10.1001/jama.289.19.2560

Dinas Kesehatan Propinsi Sulawesi Tengah. (2017). Profil Dinas Kesehatan Provinsi Sulawesi Tengah Tahun 2017. Dinas Kesehatan Propinsi Sulawesi Tengah.

Kementerian Kesehatan R.I. (2016). Profil Kesehatan Indonesia. Kementerian Kesehatan R.I. Kementerian Kesehatan R.I. (2018). Hasil Utama Riset Kesehatan Dasar Tahun 2018. Kementerian Kesehatan R.I.

Larasiska, A., \& Priyantari HN, W. (2017). Menurunkan Tekanan Darah dengan Cara Mudah pada Lansia. Indonesian Journal of Nursing Practices, 1(2), 55-63. https://doi.org/10.18196/ijnp.1261

Rezky, A. N., Nur, N., Samad, R., \& Puspitha, A. (2019). Effect of 30 Minutes Walking on Blood Pressure ff Elderly in Paccerakkang District of Makassar. Indonesian Contemporary Nursing Journal, 3(2), 36-42. https://doi.org/10.20956/icon.v3i2.3635

Sohn, A. J., Hasnain, M., \& Sinacore, J. M. (2007). Impact of exercise (walking) on blood pressure levels in African American adults with newly diagnosed hypertension. Ethnicity \& Disease, 17(3), 503-507. http://www.ncbi.nlm.nih.gov/pubmed/17985505

Surbakti, S. (2014). Pengaruh Latihan Jalan Kaki 30 Menit terhadap Penurunan Tekanan Darah pada Pasien Penderita Hipertendi di Rumah Sakit Umum Kabanjahe. Jurnal Pengabdian 
https://doi.org/10.24114/jpkm.v20i77.6868

World Health Organization. (2019). Hipertension. Who.Int. https://www.who.int/newsroom/fact-sheets/detail/hypertension\#: :text=An estimated 1.13 billion people,cause of premature death worldwide.

Yu, D. S. F., Lee, D. T. F., Woo, J., \& Hui, E. (2007). Non-Pharmacological Interventions in Older People with Heart Failure: Effects of Exercise Training and Relaxation Therapy. Gerontology, 53(2), 74-81. https://doi.org/10.1159/000096427 